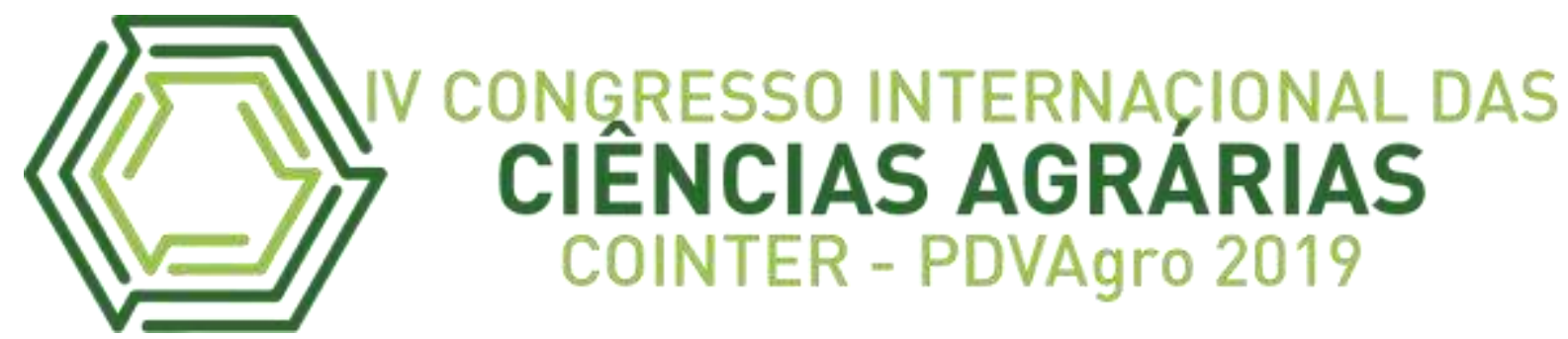

\title{
PERCEPÇÃO DE AGRICULTORES FAMILIARES SOBRE PRÁTICAS DE MANEJO DO SOLO, EM DIFERENTES SISTEMAS DE USO DA TERRA, SANTARÉM, PARÁ
}

\section{PERCEPCIÓN DE AGRICULTORES FAMILIARES SOBRE PRÁCTICAS DE MANEJO DEL SUELO, EN DIFERENTES SISTEMAS DE USO DE LA TIERRA, SANTARÉM, PARÁ}

\section{PERCEPTION OF FAMILY FARMERS ABOUT SOIL MANAGEMENT PRACTICES IN DIFFERENT LAND USE SYSTEMS, SANTARÉM, PARÁ}

\author{
Apresentação: Comunicação Oral \\ Laura Fernanda de Lima Lobato ${ }^{1}$; Misael Freitas dos $\operatorname{Santos}^{2}$; Arthur Lopes de Sousa ${ }^{3}$ Denise \\ Castro Lustosa ${ }^{4}$; Thiago Almeida Vieira ${ }^{5}$
}

DOI: https://doi.org/10.31692/2526-7701.IVCOINTERPDVAgro.2019.0002

\begin{abstract}
Resumo
No dia a dia, o homem se relaciona de diferentes formas com o ambiente, possuindo também, diferentes percepções ambientais. Diante disso, objetivou-se analisar a percepção de agricultores familiares acerca das práticas de manejo na qualidade do solo sob diferentes sistemas de uso da terra. O trabalho foi desenvolvido em oito propriedades de agricultores familiares, na comunidade rural de Cipoal, Santarém, Pará. As coletas de dados foram realizadas por meio de entrevistas estruturadas. Dentre os entrevistados, $87,5 \%$ eram do sexo masculino. Dentre as atividades praticadas pelos agricultores estavam: plantio de frutíferas, criação de galinha, quintal agroflorestal, produção de farinha, plantio de mandioca e produção de hortas. Em se tratando da renda familiar, nota-se que a agricultura familiar não é a principal fonte, visto que $62,5 \%$ dos proprietários são aposentados e as atividades na sua área são complemento na renda. As práticas de manejo nas propriedades constituem-se da adubação orgânica e química, além da utilização de fungicidas e inseticidas. A irrigação dos cultivos nas propriedades, quando realizada, é feita unicamente de forma manual. Segundo os agricultores, o manejo adequado interferiu diretamente na produtividade. Dos entrevistados, $25 \%$ declaram não serem usuários de métodos de manejo do solo em sua propriedade, todavia classificaram o solo como bom a muito bom. De modo geral, o principal indicador de qualidade do solo para os entrevistados estava ligado à produção. Observou-se que a percepção dos agricultores familiares sobre as práticas de manejo do solo ainda carece de conhecimento sobre a
\end{abstract}

\footnotetext{
${ }^{1}$ PGRNA, Universidade Federal do Oeste do Pará, laura.fll@hotmail.com

2 PPGF, UNICENTRO, misael02freitas@gmail.com

${ }^{3}$ Agronomia, Universidade Federal do Oeste do Pará, arthursousas1@hotmail.com

${ }^{4}$ Doutora em Fitopatologia, Universidade Federal do Oeste do Pará, denise.lustosa@ufopa.edu.br

${ }^{5}$ Doutor em Ciências Agrárias, Universidade Federal do Oeste do Pará, thiago.vieira@ufopa.edu.br
} 
conservação do solo. Observou-se também, falta de conhecimento técnico de parte dos responsáveis/donos das propriedades, revelando uma grande lacuna na Amazônia, a necessidade de melhorias nas ações de Extensão Rural.

Palavras-Chave: Percepção, solos, conservação, Amazônia.

\title{
Resumen
}

En el día a día, el hombre se relaciona de diferentes formas con el ambiente, poseyendo también diferentes percepciones ambientales. Frente a ello, se objetivó analizar la percepción de agricultores familiares acerca de las prácticas de manejo en la calidad del suelo bajo diferentes sistemas de uso de la tierra. El trabajo fue desarrollado en ocho propiedades de agricultores familiares, en la comunidad rural de Cipoal, Santarém, Pará. Las colectas de datos fueron realizadas por medio de entrevistas estructuradas. Entre los entrevistados, el 87,5\% eran del sexo masculino. Entre las actividades practicadas por los agricultores estaban: plantación de frutales, crianza de gallina, quintal agroforestal, producción de harina, plantación de mandioca y producción de huertos. En lo que se refiere a la renta familiar, se nota que la agricultura familiar no es la principal fuente, ya que el $62,5 \%$ de los propietarios son jubilados y las actividades en su área son complemento en la renta. Las prácticas de manejo en las propiedades se constituyen de la fertilización orgánica y química, además de la utilización de fungicidas e insecticidas. La irrigación de los cultivos en las propiedades, cuando se realiza, se realiza únicamente de forma manual. Según los agricultores, el manejo adecuado interfirió directamente en la productividad. De los entrevistados, 25\% declaran no ser usuarios de métodos de manejo del suelo en su propiedad, sin embargo clasificaron el suelo como bueno a muy bueno. En general, el principal indicador de calidad del suelo para los entrevistados estaba vinculado a la producción. Se observó que la percepción de los agricultores familiares sobre las prácticas de manejo del suelo todavía carece de conocimiento sobre la conservación del suelo. Se observó también, falta de conocimiento técnico de parte de los responsables / dueños de las propiedades, revelando una gran laguna en la Amazonia, la necesidad de mejoras en las acciones de Extensión Rural.

Palabras Clave: percepción, suelos, conservación, Amazonas.

\begin{abstract}
In everyday life, man relates different ways to interact with the environment, and having different environmental perceptions as well. So, the objective of this study was to analyze the perception of family farmers about the quality of the land in different land use systems. The work was carried out in eight farms belonging to family farmers in the rural community of Cipoal, in the municipality of Santarém, Pará. The collects were performed through structured and assisted interviews. Among the interviewees, $87.5 \%$ were male. Among the activities practiced by the farmers were: planting of fruit, raising chicken, agroforestry yard, flour production, cassava planting and vegetable gardening. In relation to family income, it is noted that family farming is not the main source, since $62.5 \%$ of the owners are retired and the activities in their area are a complement in income. The management practices in the studied properties were similar to each other: organic and chemical fertilization, besides the use of fungicides and insecticides. Concerning the irrigation practices in the crops of the visited properties, it was observed that the irrigation was unanimous in a manual way. Proper management interfered directly with productivity responses. Between the interviewees, 25\%
\end{abstract}


declare that they are not users of soil management methods on their property, however they classified the soil as good to very good. In general, the main indicator of soil quality for the interviewees was linked to production. It was observed that the perception of the family farmers on the practices of soil management still lacks knowledge about soil conservation. There was also a lack of technical knowledge on the part of the owners / owners of the properties, which made it difficult to obtain some answers during the questionnaire, but which revealed a large gap in the Amazon, the need for improvements in Rural Extension activities.

Keywords: Perception; soils, conservation, Amazon.

\section{Introdução}

Por muitas décadas, com as poucas oportunidades de intensificação de ligações e políticas voltadas ao fortalecimento de unidades familiares rurais, a escolha pelo êxodo rural permaneceu como uma atraente alternativa para obtenção de renda pelos jovens e adultos. Com relação à maior idade que permaneceu no campo, observou-se uma grande sede de conhecimento e alcance de tecnologias para o aumento de sua produção familiar (ABRAMOVAY, 1998).

Atualmente, tanto a agricultura familiar como a produção de maior escala, tendem a ser cada vez mais influenciadas por um conjunto de pressões que decorrem em seu relacionamento com o meio ambiente, independente do sistema de uso da terra.

A conservação do solo independente do sistema de uso pelo agricultor, também afeta positivamente na preservação, interação da meso e microfauna, sendo elas atores importantes na manutenção do solo e bioindicadores de fertilidade do solo (MELO et al., 2009)

Devido ao constante contato direto com a terra, o agricultor familiar tem maior preocupação com a sustentabilidade do meio em seu entorno e nos processos de produção, buscando uma manutenção que garanta a qualidade do solo em seu sistema, destacando-se o manejo empregado como o componente principal para alcançar a sustentabilidade agregada à produtividade, e quando possível reciclar e aprimorar seus conhecimentos tradicionais, em busca de maior qualidade no processo e no seu produto (LOSS et al., 2010).

A percepção ambiental tem grande importância não apenas no estudo das interações entre o homem e o ambiente, mas também é instrumento de gestão quando se trata à assuntos educacionais correlacionados à área ambiental, social e até mesmo econômica (FERNANDES, et al., 2004) 
Diante disso, o objetivo deste estudo foi analisar a percepção de agricultores familiares acerca de práticas de manejo sobre a qualidade do solo sob diferentes sistemas de uso da terra em uma comunidade rural de Santarém, Pará.

\section{Fundamentação Teórica}

\section{Conceituando percepção}

Para Marin et al. (2003), percepção pode ser conceituada como uma técnica ou maneira de como encontrar os conceitos de interação do ser humano com o mundo em diferentes análises e dimensões filosóficas, sendo um meio mais espiritualista do que materialista.

Partindo do ponto de que cada indivíduo pensa, reage e interage de uma forma diferente com os elementos da natureza e os fenômenos que ocorrem ao seu redor, Fernandes et al. (2004) definem a percepção ambiental como sendo uma tomada de consciência do ambiente pelo sujeito, ou seja, o ato de perceber o ambiente o qual está inserido, aprendendo a proteger e até mesmo sentir-se capaz de reverter fenômenos negativos causados pelo próprio ser humano.

Santos e Souza (2015) mostram que o ambiente é percebido em face de problemas ambientais, interferido diretamente na vida das pessoas e seu bem-estar. De acordo com estes autores é possível que a percepção do ambiente se dê por aspectos de viés utilitário aos seres humanos.

Nas últimas décadas, estudos partindo da percepção têm assumido importância significativa no entendimento das formas pelas quais diferentes indivíduos respondem e enfrentam à uma situação em que vivencia ou observa ao seu redor, realizada por outro indivíduo (GREGOLES et al., 2012).

Dessa forma, o estudo através de percepção ambiental torna-se imprescindível para entender as inter-relações entre homem e natureza, e assim compreender de forma mais clara e objetiva suas expectativas, anseios, satisfações e insatisfações, julgamentos e condutas acerca destas interações que muitas vezes não ocorrem de forma sustentável (FERNANDES et al., 2004). 


\section{Educação ambiental no campo}

Loureiro (1994) define educação ambiental como uma perspectiva que se insere na própria educação, formada nas relações estabelecidas com o ambiente em que se vive e a natureza, e assim conseguir separar de forma justa e sustentável a atividade econômica, de outras vertentes como a totalidade social; mente e corpo; matéria e espírito, razão e emoção etc.

A educação ambiental no campo se faz necessário pelo fato de carregar o conceito de desenvolvimento correlacionado à preocupação com as gerações futuras, além de articular princípios de justiça social, viabilidade econômica e prudência ecológica, como meta prioritária. Neste sentido, a educação ambiental mostra-se como alavanca indispensável na vida do agricultor familiar para a adoção de práticas sustentáveis, tornando-o multidimensional (LIMA, 1999).

A escola no meio rural tem papel fundamental. De acordo com Santos e Souza (2018), deve-se proporcionar dinamização da escola a partir da questão ambiental, de modo a haver participação social voltada para a responsabilidade socioambiental, oferecendo condições para um rompimento com a cultura política dominante. Para Sousa et al. (2018), a execução de atividades que possam melhorar os níveis de Educação Ambiental em uma dada comunidade pode contribuir para uma agricultura mais sustentável.

\section{Assistência técnica e extensão rural (ATER)}

A Assistência Técnica e Extensão Rural (ATER) teve sua origem no Brasil em meados de 1940, como medida de aproximação entre o produtor rural e um técnico especializado. Através da ATER, o agricultor passa a ter mais afinidade com as inovações tecnológicas integradas no meio da agricultura e pecuária, mais comumente chamada de modernização tradicional (CASTRO; PEREIRA, 2017).

Infelizmente, nem todo produtor rural têm acesso a esse tipo de serviço, uma vez que há alta demanda para pouca mão de obra especializada para a prestação destes serviços (no caso os técnicos/ extensionista rural). Exemplo disso, em um estudo de Delgado e Paumgartten (2003), dentre os seus entrevistados, apenas $11 \%$ receberam pelo menos uma vez a visita de extensionista rural.

Para Gomes et al. (2018), a assistência técnica e extensão rural serve como instrumento de melhoria na qualidade de bens e serviços prestados pelo agricultor para o mercado, sendo 
uma forma de maximizar seu sistema produtivo.

Almeida et al. (2018) abordam a ATER de duas formas, uma sendo a convencional, sendo aquela desenvolvida na Amazônia com uma formatação menos participativa; e outra mais inovadora, sendo ATER do Proambiente, na qual utiliza-se recursos de assessoramento técnico, valorização do conhecimento endógeno e muito voltada à sustentabilidade.

$\mathrm{Na}$ literatura observa-se ausência de consenso no conceito deste tão mencionado desenvolvimento sustentável. No entanto, preconiza-se uma nova extensão rural, vista como tentativa pela busca contínua de estratégias que evidenciem o desenvolvimento tridimensional: social, ambiental e econômico (CAPORAL; COSTABEBER, 2000).

Por meio da ATER, além de acesso à inovação tecnológica e técnicas eficazes para o manejo dos recursos, de forma gratuita, contínua e de qualidade, também é possível que o agricultor familiar seja comtemplado com capacitações e acesso ao crédito rural. Com isso, o agricultor familiar passa a crescer de forma sustentável, e atrelando a qualidade de vida com a obtenção de renda. (CAMPANHOLA; VALARINI, 2001).

\section{Manejo e qualidade do solo}

Carneiro et al. (2009) definem manejo do solo como sendo qualquer alteração realizada no solo, que consequentemente, modifique seus atributos químicos, físicos ou biológicos, e por esse motivo, a avaliação periódica torna-se necessária para o seu controle de qualidade e à produtividade da cultura, visando a sustentabilidade do sistema.

Segundo Panchiki et al. (2011), dependendo do manejo a que o solo for submetido, podem haver alterações nas suas propriedades e fertilidade, podendo ser observadas diretamente por meio de manifestação nas plantas, sendo no seu melhor desenvolvimento/ crescimento, ou até mesmo retardando o crescimento.

O uso de sistemas convencionais e sem prévio planejamento de manejo do solo, pode elevar as perdas de elementos essenciais para o desenvolvimento do cultivo por meio de erosão hídrica, fazendo com que aumentem os custos financeiros e os riscos ambientais. Como por exemplo, concentrações de nutrientes e matéria orgânica, podem alterar significativamente de forma negativa ou positiva, de acordo com o sistema de manejo de solo, afetando assim, sua qualidade (HERNANI; KIRIHARA; SILVA, 1999). 


\section{Metodologia}

O trabalho foi desenvolvido em oito propriedades de agricultores familiares, na comunidade rural do Cipoal, no município de Santarém, Pará (02 $\left.26^{\prime} 35^{\prime \prime} \mathrm{S} 54^{\circ} 42^{\prime} 30^{\prime \prime} \mathrm{W}\right)$.

As coletas de dados foram realizadas por meio de entrevistas estruturadas e assistidas, com perguntas abertas e fechadas, a fim de captar a percepção dos agricultores quanto às diferentes práticas de manejo adotadas, aspectos socioeconômicos, culturais e ambientais, conforme metodologia proposta por Alencar et al. (2013). As perguntas foram feitas sem induzir as respostas com opções pré-definidas, deixando o entrevistado a vontade para expressar sua realidade.

Foi realizada a caracterização da percepção dos agricultores em três sistemas de uso da terra: quintal agroflorestais, floresta secundária (capoeira) e plantação de citrus.

Foram averiguadas informações acerca do perfil do entrevistado como: gênero, faixa etária, estado civil, grau de escolaridade e renda mensal e coletados também dados sobre a propriedade como: tamanho, tempo que as famílias desenvolvem a agricultura na área de estudo, bem como as culturas que são cultivadas.

Os dados quantitativos foram tabulados em planilha Excel for Windows ${ }^{\circledR}$ e os dados qualitativos foram avaliados pela Análise de Conteúdo, conforme recomendações de Câmara (2013). Além disso, buscou-se entender as noções a respeito do conceito e funções do solo, manejo e conservação, a utilização de práticas de manejo e importância de utilizá-las, existência de floresta nativa, entre outros.

\section{Resultados e Discussão}

\section{Perfil dos entrevistados}

A faixa etária dos entrevistados variou de 39 e 83 anos, com média de 62,5 anos, sendo estes $87,5 \%$ do sexo masculino. A média de idade encontrada pode indicar possível envelhecimento da comunidade, processo que o jovem se distancia da agricultura e/ou do rural, em busca de emprego ou formação no espaço urbano.

A idade média de inserção na agricultura familiar entre os entrevistados foi de 39 anos (Tabela 1). Carneiro e Castro (2007) afirmam que 60\% dos jovens residentes no meio rural gostariam de permanecer no campo exercendo alguma função na agricultura familiar, no 
entanto, por falta de oportunidades, migram para o meio urbano em busca de melhor qualidade de vida.

Tabela 1: Idade e tempo de experiência na agricultura dos entrevistados na Comunidade de Cipoal, Santarém, Pará.

\begin{tabular}{cccc}
\hline Entrevistado & Idade & $\begin{array}{c}\text { Tempo de prática } \\
\text { na agricultura }\end{array}$ & $\begin{array}{c}\text { Idade de início na } \\
\text { agricultura }\end{array}$ \\
\hline 1 & 51 & 15 & 36 \\
2 & 68 & 49 & 19 \\
3 & 39 & 20 & 19 \\
4 & 49 & 24 & 25 \\
5 & 83 & 60 & 23 \\
6 & 71 & 55 & 16 \\
7 & 59 & 22 & 37 \\
8 & 69 & 12 & 57 \\
\hline Média & 62,5 & 31,1 & 29 \\
\hline
\end{tabular}

Fonte: Própria (2019)

Dutra e Higuchi (2018) assinalam as crianças como público de grande potencial para a estudos de percepção ambiental, devido a expressão com sinceridade, e informações de leitura visual de ações de adultos, trazendo consigo pontos negativos que podem ser melhorados através de ações de estratégia.

Majoritariamente os entrevistados são casados ou em união estável. Destaca-se ainda uma entrevistada do sexo feminino, visto que a mulher tem importante papel na agricultura, que além de muitas das vezes ser a precursora na unidade familiar, é atuante direta na produção, e encara desafios e responsabilidades que para a sociedade atual ainda é papel apenas do homem (KARAM, 2004).

A escolaridade variou de pessoas que não estudaram até quem tenha concluído o ensino médio, sendo baixa a média do nível de escolaridade (Figura 1). Para Borges e Pinheiro (2002), é um desafio coletar dados com pessoas de baixa escolaridade devido a possibilidade de prejuízos metodológicos uma vez que algumas respostas podem ser generalizadas ou até mesmo respondidas de modo equivocado. 
Figura 1: Relação de idade e anos de estudo dos entrevistados na Comunidade Cipoal, Santarém, Pará.

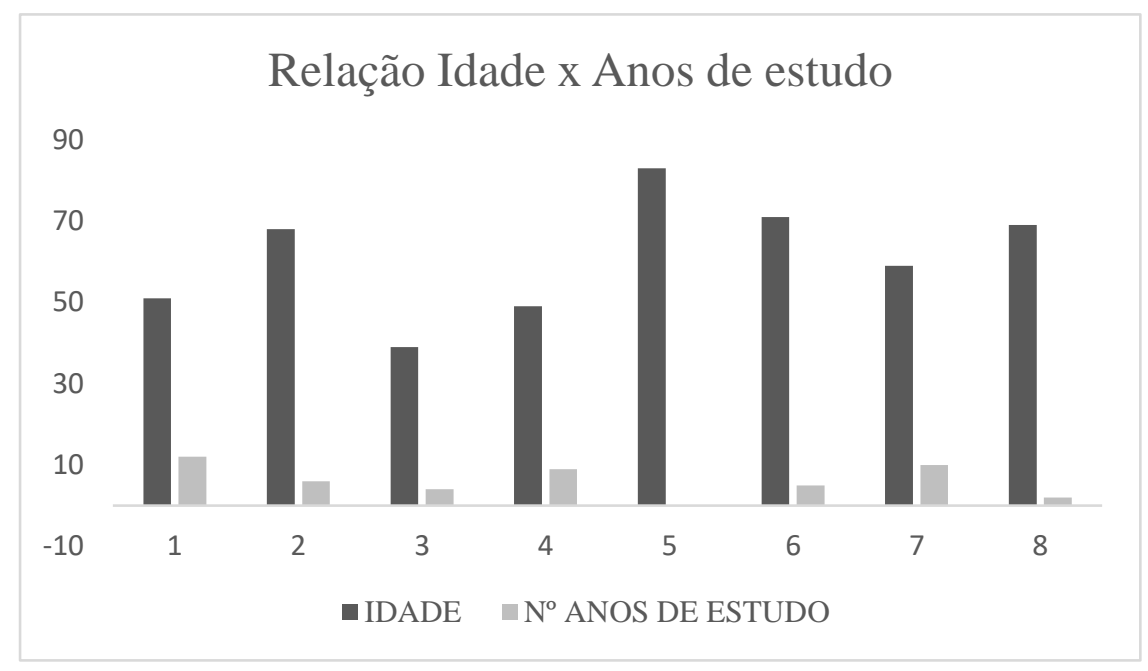

Fonte: Própria (2019)

\section{Características das propriedades}

O tamanho das propriedades variou de 0,27 a 12 hectares, com média de 4,6 ha, resultado muito inferior comparado ao estudo de Shimabukuro et al. (1997), onde estes apontam que o tamanho médio das propriedades rurais da região Amazônica, em sua maioria, variam entre 40 e 100 ha. Estes mesmos valores também estão abaixo da média em se tratando do padrão de áreas de propriedades informado pelo INCRA (1998).

O número de atividades produtivas, ligadas à agricultura, variou de um a três por propriedade. Dentre as atividades praticadas pelos agricultores estavam: plantio de frutíferas, criação de galinha, quintal agroflorestal, produção de farinha, plantio de mandioca e produção de hortas (Tabela 2).

Tabela 2: Culturas produzidas nas propriedades estudadas na Comunidade Cipoal, Santarém, Pará.

\section{Nome comum $\quad$ Frequência $(\%) \quad$ Tipo de cultivo}

\begin{tabular}{lcl}
\hline Abacate & 12,5 & Perene \\
Acerola & 38,5 & Perene \\
Banana & 38,5 & Perene \\
Coco & 12,5 & Perene \\
Cupuaçu & 25 & Perene \\
Feijão & 12,5 & Temporário
\end{tabular}




$\begin{array}{lcl}\text { Laranja } & 75 & \text { Perene } \\ \text { Limão } & 25 & \text { Perene } \\ \text { Legumes } & 12,5 & \text { Temporário } \\ \text { Macaxeira } & 25 & \text { Temporário } \\ \text { Mandioca } & 37,5 & \text { Temporário } \\ \text { Manga } & 37,5 & \text { Perene } \\ \text { Milho } & 12,5 & \text { Temporário } \\ \text { nta do reino } & 12,5 & \text { Perene } \\ \text { Tangerina } & 37,5 & \text { Perene }\end{array}$

Fonte: Própria (2019)

Em relação à diversidade de espécies cultivadas nas propriedades, observou-se que a grande maioria é de frutíferas, com destaque para laranja (75\%) (Tabela 2; Figura 2), resultado semelhante ao estudo de Vieira et al. (2012), em que Citrus sinensis (laranja) e Citrus limonia (limão) obtiveram frequência de 87,5 e 75\%, respectivamente, em 24 quintais agroflorestais na Amazônia paraense. A preferência por espécies de citrus pode estar relacionada às questões culturais, muito influenciadas pelos benefícios alimentares e medicinais destas espécies e de comercialização. 
Figura 2: Aspectos do cultivo de Citrus sp. na comunidade do Cipoal, Santarém, Pará. Fonte: Acervo dos autores.

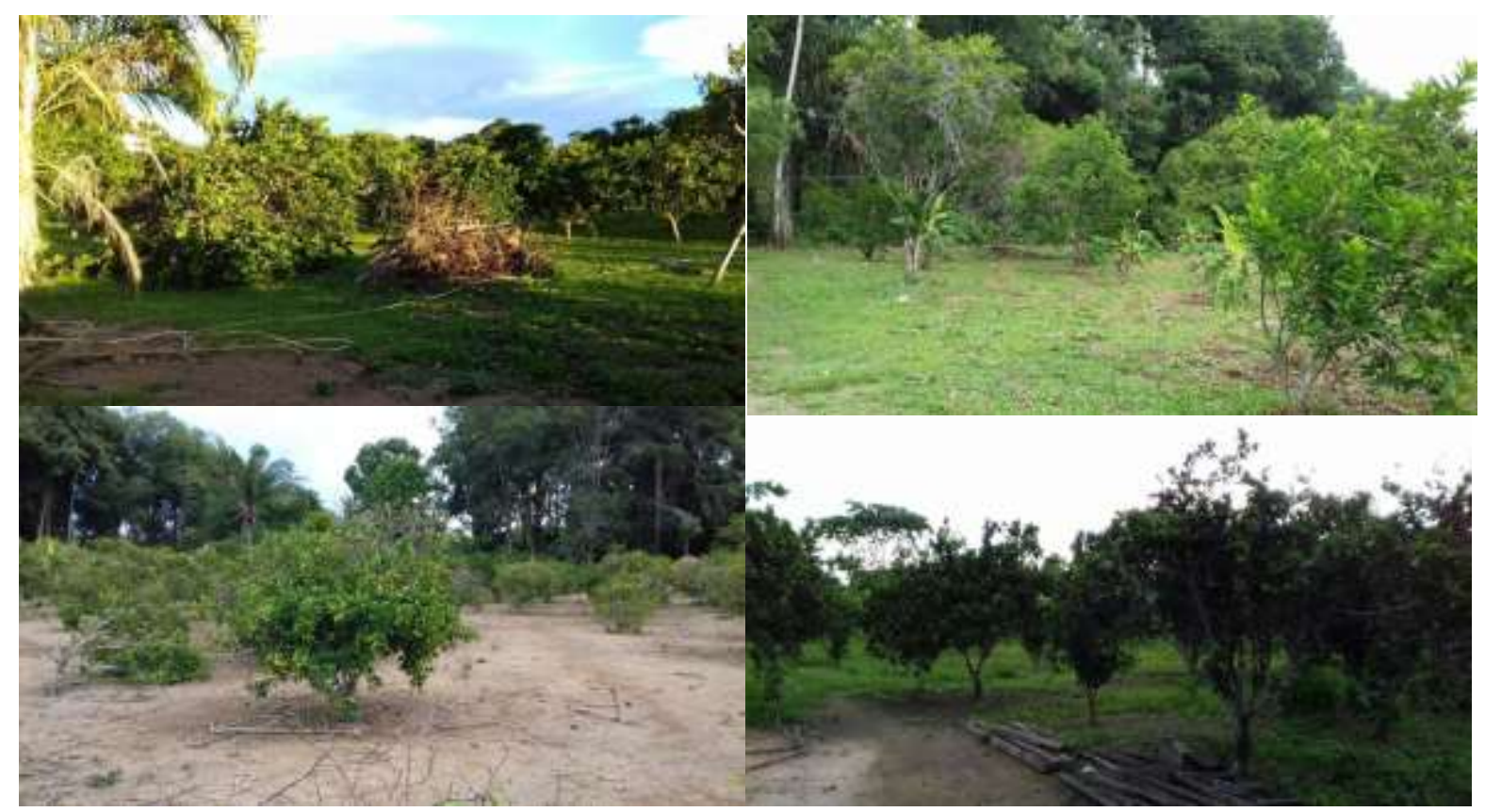

Fonte: Própria (2019)

Segundo Borrajo et al. (2015), a citricultura ganha espaço gradativamente nos quintais agroflorestais. Vale salientar que a escolha por frutíferas e hortaliças também possui ligação direta com a viabilidade econômica e necessidades do mercado (ABDO; MARTINS, 2008).

De modo geral, os agricultores que participaram da pesquisa, detêm de consciência ambiental ao escolher uma opção alternativa que garanta a sustentabilidade em seus sistemas de cultivo mesmo com o passar dos anos. Além disso, neste modelo de agricultura, não há grande demanda de implementos agrícolas, uma vez que o manejo das espécies é satisfatório apenas com práticas manuais.

Assim, a aplicação de entrevistas, além de ser instrumento de análise de opiniões, interliga os problemas apontados com possíveis soluções para os mesmos, sendo um modelo de gestão participativa e apontamentos de estratégias em conjunto, e por estes motivos requer um olhar apurado por parte do entrevistador (SILVA; CÂNDIDO; FREIRE, 2009).

\section{Percepção sobre manejo e qualidade do solo}

Para os agricultores entrevistados na Comunidade Cipoal, a importância do solo das suas propriedades variou entre: fonte de alimento, cultivo e fonte de renda (Tabela 3). 
Tabela 3: Importância do solo para os produtores de propriedades estudadas na comunidade do Cipoal, Santarém, Pará.

\begin{tabular}{cc}
\hline Importância do solo para o produtor & Frequência $(\boldsymbol{\%})$ \\
\hline Fonte de alimento & 37,5 \\
Fonte de renda & 37,5 \\
Cultivo & 25 \\
\hline
\end{tabular}

Fonte: Própria (2019)

Em se tratando da fonte de renda, nota-se que a agricultura familiar não é a principal, uma vez que $62,5 \%$ dos proprietários são aposentados e as atividades na sua área são complementos na renda.

As práticas de manejo nas propriedades estudadas foram similares entre si, sendo estas: adubação orgânica e química, além da utilização de fungicidas e inseticidas (Tabela 4). Coelho e França (1995) afirmam que com as constantes inovações no meio rural, o agricultor passa a ser refém de algumas tecnologias, tais como a fertilização do solo visando maior produção.

Tabela 4: Relação das práticas de manejo com a produtividade, nas propriedades estudadas na Comunidade Cipoal, Santarém, Pará.

\begin{tabular}{ccc}
\hline Propriedade & Práticas de manejo utilizadas & $\begin{array}{c}\text { Diferença observada na } \\
\text { produtividade após o } \\
\text { manejo }\end{array}$ \\
\hline 1 & Não se aplica & - \\
2 & Adubação orgânica & Maior produção \\
3 & Adubação orgânica e química & Maior produção \\
4 & Aplicação de fungicida, inseticida e calcário & Maior produção \\
5 & Não se aplica & - \\
6 & Adubação orgânica e química & Maior produção \\
8 & Adubação e roçagem & Maior produção \\
\hline
\end{tabular}

Fonte: Própria (2019)

O manejo adequado interferiu diretamente nas respostas a respeito da produtividade. Dos entrevistados, $25 \%$ declaram não serem usuários de métodos de manejo do solo em sua propriedade, todavia classificaram o solo como bom a muito bom. 
A escolha de parâmetros para a estruturação de entrevistas na avaliação de percepção ambiental, deve ser estruturadas de acordo com as respostas que espera-se serem obtidas, dando espaço ao entrevistado para assim impetrar o máximo de informações através do seu conhecimento tradicional, adaptando sempre estas perguntas com a ciência cognitiva, afinal, a percepção ambiental é a avaliação do ser humano para com seu mundo exterior (DACANAL; LABAKI; SILVA, 2010).

Kamiyama et al. (2011), afirmam que produtores orgânicos costumam ser mais concisos em questionamentos relacionados aos atributos físicos e biológicos do solo em que cultiva, sendo também usuários mais racionais comparados aos conservacionistas, os quais apresentaram uma percepção ambiental inferior.

Um resultado relevante é a utilização de fungicida e inseticida nos cultivos, umas vez que a agricultura familiar vêm passando por um processo de modificação, em que a utilização deste produtos passa a ser uma alternativa para o aumento da produtividade, onde o foco maior é o lucro final da produção familiar (SILVA et al., 2005).

Os dados apontam que o principal indicador de qualidade do solo está ligado à produção. A diversificação e continuidade do sistema de cultivo também é um fator importante, pois estimula as interações e entre os componentes do solo. Para Vezzani e Mielniczuk (2009), com a heterogeneidade de espécies, acumula-se uma maior quantidade de matéria e compostos orgânicos no solo, fazendo com que o solo assim, atinja maior qualidade. Vieira et al. (2016) alertam que a remoção da serrapilheira de quintais agroflorestais, prática comum na Amazônia, pode ter sido o principal motivo para a redução dos níveis de matéria orgânica do solo sob os sistemas estudados por estes autores.

Quanto às práticas de irrigação nos cultivos das propriedades visitadas, observou-se que foi unânime a irrigação de forma manual. A região do Cipoal está localizada no Planalto Santareno, tendo que em muitas regiões utiliza-se da prática de irrigação, para garantir o fornecimento de água ao solo e às plantas. De acordo com Franchini et al. (2009), as práticas de irrigação são indispensáveis para o melhor desenvolvimento das raízes das plantas, para o aumento do volume de água armazenada no solo, assim como suprir as necessidades hídricas das plantas.

De modo geral, dependendo do público estudado, este poderá apresentar diferentes níveis de conhecimento acerca dos temas abordados na avaliação de percepção ambiental como foi o caso deste estudo, e assim permitem pleito sobre o tema abordado, enfatizando novas 
investigações nos temas que mais apresentaram ausência de conhecimento onde era tão importante se ter (PEDRINI et al., 2016).

Dessa forma, observou-se que a percepção dos agricultores familiares sobre as práticas de manejo do solo ainda possui muitas lacunas de conhecimento acerca do tema. Em geral, as práticas de manejo praticadas foram adquiridas pela transmissão de conhecimento entre gerações, além do senso comum. Observou-se também, falta de conhecimento técnico de parte dos responsáveis/donos das propriedades, o que dificultou a obtenção de algumas respostas durante o questionário, revelando assim, a necessidade de melhorias nas ações de Extensão Rural.

\section{Conclusões}

O solo é visto pelos agricultores como fornecedor de alimentos e possibilidade de obtenção de renda a partir das culturas cultivadas por eles. A qualidade do solo é percebida por meio da produção obtida nas propriedades.

Observou-se uma imensa carência de Assistência Técnica e Extensão Rural (ATER) a esses agricultores familiares, uma vez que em meio a tantas inovações e pesquisas voltadas à ciência do solo, necessita-se de capacitações e atualização sobre as melhores formas e práticas de manejo, o que reflete diretamente na maior produção de cada uma das espécies cultivadas. Isto mostra o papel da Extensão Rural, em contribuir com o conhecimento do solo junto ao homem do campo.

\section{Referências}

ABDO, M.T.V.N.; VALERI, S.V.; MARTINS, A.L.M. Sistemas agroflorestais e agricultura familiar: uma parceria interessante. Revista Tecnologia \& Inovação Agropecuária, p 50-59, 2008 .

ALENCAR, G.V.; MENDONÇA, E.S.; OLIVEIRA, T.S.; JUCKSCH, I.; CECON, P.R. Percepção ambiental e uso do solo por agricultores de sistemas orgânicos e convencionais na Chapada da Ibiapaba, Ceará. Revista de Economia e Sociologia Rural, v.51, n.2, p.217-236, 2013.

ALMEIDA, E. N.; JUNIOR, S. B.; XIMENES, T.; POÇA, R. R.; YARED, J.O modelo de assistência e extensão rural do proambiente: uma inovação na agroecologia/The model of technical assistance and rural extension of the proambiente: an innovation in agroecology. Brazilian Journal of Development, v. 4, n. 6, p. 2939-2950, 2018. 
ARAÚJO, A.L.; ALVES, A.G.C.; ROMERO, R.E.; FERREIRA, T.O. Etnopedologia: uma abordagem das etnociências sobre as relações entre as sociedades e os solos. Ciência Rural, v.43, n.5, p.854-860, 2013.

BORGES, L. O.; PINHEIRO, J. Q. Estratégias de coleta de dados com trabalhadores de baixa escolaridade. Estudos de Psicologia, v. 7, 2002.

BORRAJO, F.D.; CORREA, A.S.S.; MARQUES, D.C.S.; LIMA, M.N. A.; ALMEIDA, G.M.; SALDANHA, E.C.M. Substratos para a Produção de Mudas de Laranja (Citrus sinensis,(L.) Osbeck) em Capitão Poço, Pará. In: CONGRESSO BRASILEIRO DE CIÊNCIA DO SOLO, 35, 2015, Natal. Anais... Sociedade Brasileira de Ciência do Solo, 2015.

CÂMARA, R.H. Análise de conteúdo: da teoria à prática em pesquisas sociais aplicadas às organizações. Revista Interinstitucional de Psicologia, v. 6, n. 2, p.179-191, 2013.

CAMPANHOLA, Clayton; VALARINI, Pedro José. A agricultura orgânica e seu potencial para o pequeno agricultor. Cadernos de Ciência \& Tecnologia, v. 18, n. 3, p. 69-101, 2001.

CAPORAL, Francisco Roberto; COSTABEBER, José Antônio. Perspectivas para uma Nova Extensão Rural. Revista Agroecologia e Desenvolvimento Rural Sustentável, v. 1, n. 01, p. 16-37, 2000.

CARNEIRO, M.J.; CASTRO, E.G. Juventude rural em perspectiva. Mauad Editora Ltda, 2007.

CARNEIRO, Marco Aurélio et al. Atributos físicos, químicos e biológicos de solo de cerrado sob diferentes sistemas de uso e manejo. Revista Brasileira de Ciência do solo, v. 33, n. 1, 2009.

CARNIELLO, M.A.; SILVA, R.S.; CRUZ, M.A.B.; GUARIM NETO, G. Quintais urbanos de Mirassol D’Oeste-MT, Brasil: uma abordagem etnobotânica. Acta Amazonica, v.40, n.3, p. $451-470,2010$.

CASTRO, César Nunes de; PEREIRA, Caroline Nascimento. Agricultura familiar, assistência técnica e extensão rural e a política nacional de Ater. Rio de Janeiro: IPEA, 2017.

COELHO, A.M.; FRANÇA, G.E. Seja o doutor do seu milho: nutrição e adubação. 2.ed. Piracicaba: Potafos, 1995.

DACANAL, C.; LABAKI, L.C.; SILVA, T.M.L. da. Vamos passear na floresta! O conforto térmico em fragmentos florestais urbanos. Ambient. constr., v. 10, n. 2, p. 115-132, 2010.

DUTRA, G.K.M.; HIGUCHI, M. I.G. ENVIRONMENTAL PERCEPTIONS OF CHILDREN WHO LIVE IN DEGRADED SPACES IN THE AMAZON. Ambient. soc., v. 21, e00871, 2018.

FERNANDES, R. S; SOUZA, J. V.; PELISSARI; V. B.; FERNANDES, S. T. Uso da percepção ambiental como instrumento de gestão em aplicações ligadas às áreas educacional, social e 
ambiental. Encontro Nacional de Pós-Graduação e Pesquissa em Ambiente e Sociedade, v. 2, n. 1, p. 1-15, 2004.

FRANCHINI, J.C.; DEBIASI, H.; SACOMAN, A.; NEPOMUCENO, A.L.; FARIAS, J.R. B. Manejo do solo para redução das perdas de produtividade pela seca. Londrina: Embrapa Soja, 2009.

GOMES, Marcia Campos; NOGUEIRA, Ana Claudia Fernandes; DA COSTA, Francimara Souza. Assistência Técnica e Extensão Rural em comunidades rurais do sul do Amazonas. Novos Cadernos NAEA, v. 21, n. 2, 2018.

GREGOLES, Thais Blaya Leite; PINTO, Wagner de Jesus; PERES, Frederico. Percepção de riscos do uso de agrotóxicos por trabalhadores da agricultura familiar do município de Rio Branco, AC. Revista Brasileira de Saúde Ocupacional, v. 37, n. 125, 2012.

HERNANI, L. C.; KURIHARA, C. H.; SILVA, WM da. Sistemas de manejo de solo e perdas de nutrientes e matéria orgânica por erosão. Revista Brasileira de Ciência do Solo, v. 23, n. $1,1999$.

INSTITUTO NACIONAL DE COLONIZAÇÃO E REFORMA AGRÁRIA - INCRA. Mapa dos Projetos de Assentamento do INCRA (digital), 1998.

KAMIYAMA, A.; MARIA, I. C. de.; SOUZA, D. C. C. de.; SILVEIRA, A. P. D. Percepção ambiental dos produtores e qualidade do solo em propriedades orgânicas e convencionais. Bragantia, v. 70, n. 1, p. 176-184, 2011.

KARAM, K. F. A mulher na agricultura orgânica e em novas ruralidades. Estudos feministas, v. 12, n. 1, p. 303, 2004.

LIMA, L.C.M; SANTOS, T.E.M.; SOUZA, E.R; OLIVEIRA, E.L. Práticas de manejo e conservação do solo: percepção de agricultores da região Semiárida pernambucana. Revista Verde de Agroecologia e Desenvolvimento Sustentável, v.11, n. 4, p. 148-153, 2016.

LOUREIRO, Carlos Frederico Bernardo. Educação ambiental transformadora. Identidades da educação ambiental brasileira. Brasília: Ministério do Meio Ambiente, p. 65-84, 2004.

MARIN, Andréia Aparecida; TORRES OLIVEIRA, Haydée; COMAR, Vito. Uma educação ambiental num contexto de complexidade faz o campo teórico da percepção. INCI, Caracas, v. 28 , n. 10 , p. 616-619, out. 2003.

PEDRINI, A. de G.; BROTTO, D. S.; SANTOS, T. V., L., L.; NUNES, R. M. Percepção ambiental sobre as mudanças climáticas globais numa praça pública na cidade do Rio de Janeiro (RJ, Brasil). Ciênc. educ. (Bauru), v. 22, n. 4, p. 1027-1044, 2016.

SANCHEZ, M.; MIRANA, P.; DUIVENVOORDEN, J. Plantas, suelos y paisajes: ordenamientos de la naturaleza por los indígenas Miraña de la Amazonía colombiana. Acta Amazônica, v. 37, n. 4, p. 567-582, 2007.

SANTOS, Franco Porto dos; SOUZA, Lucas Barbosa. Estudo da percepção da qualidade ambiental por meio do método fenomenológico. Mercator (Fortaleza), v. 14, n. 2, p. 57-74, 
2015.

SANTOS, S. L. F.; SOUZA, R. P. Educação ambiental nas escolas rurais: contribuições das pesquisas científicas no Brasil. Revista Eletrônica do Mestrado em Educação Ambiental, v. 35, n. 2, p. 105-124, 2018.

SCHMITZ, H. A transição da agricultura itinerante na Amazônia para novos sistemas. Revista Brasileira de Agroecologia, v.2, n.1, 2007.

SHIMABUKURO, Y. E.; MELLO, E. M. K.; MOREIRA, J. C.; DUARTE, V. Segmentação e classificação da imagem sombra do modelo de mistura para mapear desflorestamento na Amazônia. INPE. 1997.

SILVA, J. M.; SILVA, E.; FARIA, H. P.; PINHEIRO, T. M. M. Agrotóxico e trabalho: uma combinação perigosa para a saúde do trabalhador rural. Ciência \& saúde coletiva, v. 10, p. 891-903, 2005.

SILVA, T.S.; CANDIDO, G.A.; FREIRE, E.M.X. Conceitos, percepções e estratégias para conservação de uma Estação Ecológica da Caatinga nordestina por populações do seu entorno. Sociedade \& Natureza, v. 21, n. 2, p. 23-37, 2009.

SOUSA, D. G.; MARQUES, D. J. S.; SERRA, R. B. G.; SOUSA, A. C.; FIGUEIREDO, G. J. A. Uma percepção ambiental de agricultores da comunidade Águas Turvas sobre o uso de agrotóxico na região da bacia hidrográfica do Rio Gramame, João Pessoa (PB). Revista Brasileira de Educação Ambiental, v. 13, n. 2, p. 332-339, 2018.

VALE JUNIOR, J.F.; SCHAEFER, C.E.G.R.; COSTA, J.A.V. Etnopedologia e transferência de conhecimento: diálogos entre os saberes indígena e técnico na Terra Indígena Malacacheta, Roraima. Revista Brasileira de Ciência do Solo, v. 31, p. 403-412, 2007.

VEZZANI, F.M.; MIELNICZUK, J. Uma visão sobre qualidade do solo. Revista brasileira de ciência do solo, v. 33, n. 4, p. 743-755, 2009.

VIEIRA, T.A.; ROSA, L.S.; SANTOS, M.M.L.S. Agrobiodiversidade de quintais agroflorestais no município de Bonito, Pará. Revista de Ciências Agrárias, v.55, p.159-166, 2012.

VIEIRA, T.A.; ROSA, L.S.; SANTOS, M.M.L.S.; SANTOS, C.A.A.; LUSTOSA, D.C.; SANTOS, A.P.A. Chemical properties of soils in agroforestry homegardens and other land use systems in Eastern Amazon, Brazil. African Journal of Agricultural Research, v.11, n.29, p.2616-2622, 2016. 